03;05.1

\title{
Способ сохранения ориентации плоского ударника, ускоряемого в канале сжатым газом
}

\author{
() Д.Е. Гук, Е.Е. Мешков ๙ \\ Саровский физико-технический институт НИЯУ МИФИ, Саров, Нижегородская обл., Россия \\ 『 E-mail: eemeshkov@gmail.com
}

Поступило в Редакцию 21 ноября 2017г.

В окончательной редакции 11 апреля 2019г.

Принято к публикации 11 апреля 2019г.

\begin{abstract}
Задача ускорения в цилиндрическом канале сжатым газом (в частности, продуктами детонации смеси ацетилена с кислородом) тонкого плоского ударника имеет отношение к, „проблеме падающего листа бумаги“, поскольку движение ударника в канале неустойчиво по отношению к боковому смещению. Это может приводить к нарушению симметрии полета ударника, его перекосу и резкому снижению достигаемой скорости ударника. Экспериментально показана возможность сохранения ориентации ударника за счет ограничения его бокового смещения путем равномерного расположения на внутренней поверхности канала (по образующим поверхности) нескольких тонких нитей полимерной лески.
\end{abstract}

Ключевые слова: плоский тонкий ударник, сжатый газ, ограничение бокового смещения ударника, удар по слою воды.

DOI: 10.21883/PJTF.2019.14.48016.17128

Результаты экспериментов [1] демонстрируют возможность достижения высокой скорости (более $200 \mathrm{~m} / \mathrm{s}$ ) тонкого плоского ударника, ускоряемого в цилиндрическом канале давлением продуктов детонации смеси ацетилена с кислородом. Давление продуктов детонации сравнительно невелико, но вследствие высокой температуры и соответственно высокой скорости звука при ускорении ударника в достаточно протяженном канале возможно достижение высоких скоростей.

При ударе подобного ударника по слою воды формируется нестационарная затухающая ударная волна (волна Тейлора), при выходе которой на свободную границу слоя вследствие развития неустойчивости может формироваться разлетающееся облако диспергированной воды. При этом стоит задача не только получения достаточно интенсивной волны Тейлора, но и обеспечения высокой симметрии удара по слою воды.

Однако, как показывает опыт, работа подобного устройства является нестабильной и может нарушаться вследствие перекоса ударника. Можно предположить, что такое нарушение имеет связь с „проблемой падающего листа бумаги“ $[2,3]$. В процессе свободного падения лист бумаги (как и древесный лист) совершает колебательные перемещения подобно маятнику. В соответствии с расчетными оценками [4] плоский тонкий ударник, ускоряемый сжатым газом в цилиндрическом канале, должен быть устойчив относительно малого наклона его плоскости к оси канала, т. е. существуют механизмы, выравнивающие положение ударника. Однако это не препятствует боковому смещению ударника и его касанию боковой стенки канала. При движении ударника вдоль канала с большой скоростью это касание может приводить к резкому торможению касающейся части ударника и такому нарушению симметрии его полета, которое не успевает стабилизироваться до конца полета по каналу.

Далее описан метод ограничения бокового смещения ударника, который приводит к устранению касания ударником стенки канала и существенному снижению вероятности нарушения симметрии полета ударника.

В экспериментах использовалась описанная в [1] конструкция ударной трубы со следующими параметрами:

- внутренний диаметр канала ударной трубы $35.0 \mathrm{~mm}$;

- протяженность заполняемой смесью ацетилена с кислородом камеры $40.0 \mathrm{~mm}$;

- протяженность изготовленного из оргстекла ускорительного канала $60.0 \mathrm{~mm}$;

- диаметр ударника 34.5-34.6 mm. В качестве заготовки для ударника использовался материал корпуса CD-бокса толщиной $\sim 1 \mathrm{~mm}$ с разнотолщинностью $\sim 0.01 \mathrm{~mm}$.

Для ограничения бокового смещения ударника в процессе его ускорения на внутренней поверхности ускорительного канала по образующим располагалось несколько нитей полимерной лески диаметром $0.12 \mathrm{~mm}$. В этом случае боковое смещение ударника в сторону от оси канала ограничивается леской, тем самым устраняется касание ударника о стенку канала. При этом должны резко снижаться площадь касания и тормозящий момент, возникающий при контакте ударника и лески, по сравнению со случаем контакта ударника со стенкой канала.

В связи с этим возникает задача определения такого шага углового распределения нитей лески на поверхности канала, который исключает возможность касания ребром летящего ударника внутренней поверхности ка- 
Значения скоростей ударника и фронта разлетающейся воды

\begin{tabular}{l|c|c}
\hline $\begin{array}{c}\text { Номер } \\
\text { опыта }\end{array}$ & $\begin{array}{c}\text { Скорость } \\
\text { ударника, } \\
\mathrm{m} / \mathrm{s}\end{array}$ & $\begin{array}{c}\text { Скорость фронта } \\
\text { облака } \\
\text { диспергированной } \\
\text { воды, } \mathrm{m} / \mathrm{s}\end{array}$ \\
\hline $4-13$ & 250 & 257 \\
$4-14-1$ & 246 & 223 \\
$4-14-2$ & 250 & 227 \\
$4-26$ & 250 & 216 \\
$4-28$ & 244 & 192
\end{tabular}

нала. Для определения такого расположения нитей лески рассмотрим схему сечения канала с ударником (рис. 1).

Здесь ударник с радиусом $r$ смещен относительно оси канала на величину $\Delta$ до касания со стенкой канала с радиусом $R$. Проведем прямую в произвольном направлении под углом $\alpha$ к вектору смещения центра ударника относительно оси канала. Обозначим расстояние от стенки канала до ударника в этом направлении как $\delta$. Тогда, используя теорему косинусов, можно записать уравнение

$$
r^{2}=\Delta^{2}+(R-\delta)^{2}-2 \Delta(R-\delta) \cos \alpha .
$$

Воспользовавшись тем обстоятельством, что в нашем случае $\delta / R<<1$, можно получить приближенную зависимость $\delta$ от угла $\alpha$ в виде

$$
\delta=\frac{r^{2}+2 \Delta R \cos \alpha-\Delta^{2}-R^{2}}{2(\Delta \cos \alpha-R)} .
$$

Подставляя в формулу (2) известные значения $r, R, \Delta$, получим зависимость $\delta(\alpha)$ для двух вариантов диаметра ударника в пределах поля допуска на его изготовление (рис. 2). На этом же рисунке приведена горизонтальная линия, соответствующая диаметру лески $0.12 \mathrm{~mm}$. Видно, что приближенно для всех значений $\alpha<60^{\circ}$ боковое смещение ударника ограничивается леской и, таким образом, предотвращается касание стенки канала.

При экспериментальной проверке эффективности действия ограничителя бокового смещения ударника на внутренней поверхности канала ударной трубы устанавливались три равномерно размещенные нити лески Balsax Focus диаметром $0.12 \mathrm{~mm}$ (т.е. с шагом $2 \alpha=120^{\circ}$ ). Геометрия составных частей ударной трубы такая же, как в опытах [1] (см. выше).

При проведении опытов камера заполнялась стехиометрической смесью ацетилена с кислородом через газовводы путем прокачивания через нее объема смеси, в 5 раз превышающего объем камеры (по результатам экспериментов [5] этого достаточно для обеспечения чистоты газа в объеме камеры). Инициирование детонации смеси осуществляется с помощью искрового разряда в искровом промежутке. Для регистрации разгона ударника использовалась высокоскоростная кинокамера (скоростной фоторегистратор СФР в режиме лупы времени).

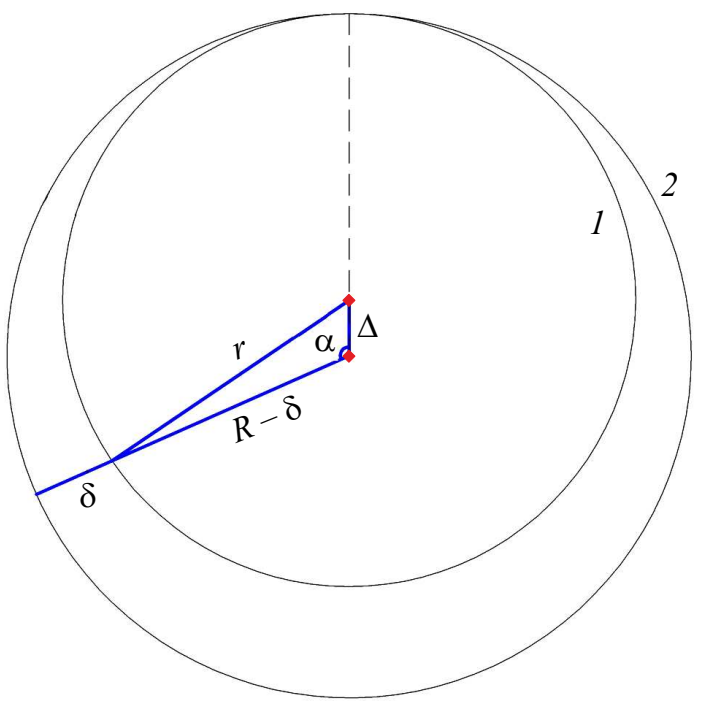

Рис. 1. Схема сечения канала со смещенным ударником (касающимся стенки канала). 1 - ударник, $2-$ поверхность стенки канала.

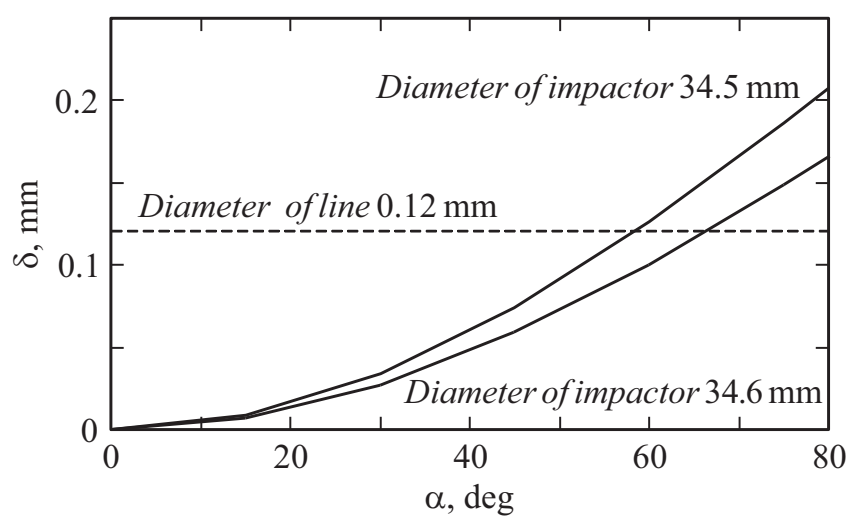

Рис. 2. Зависимость $\delta(\alpha)$ для двух вариантов диаметра ударника в пределах поля допуска на его изготовление.

$X-t$-диаграммы ускорения ударника в канале ударной трубы и фронта разлета облака диспергированной воды при выходе на свободную поверхность слоя воды ударной волны (волны Тейлора) определялись по кадрам фотохронограммы. Результаты этих измерений аппроксимировались полиномом третьей степени, после дифференцирования которого определялись скорости ударника на вылете из канала ударной трубы и фронта разлетающегося облака диспергированной воды. Степень симметрии удара по слою воды и волны Тейлора в слое оценивалась по форме облака диспергированной воды. При симметричном (без перекоса) ударе по слою воды верхняя часть облака будет симметричной плоской со скошенными краями, что связано с боковой разгрузкой. И в результате облако в этом случае должно иметь форму усеченного конуса, а в боковой проекции изображение облака имеет вид трапеции. При перекосе ударника эта картина нарушается. 
В таблице приведены полученные в опытах значения скоростей ударника и фронта разлетающейся воды. В серии из пяти опытов только в одном случае (опыт 4-28) было зарегистрировано существенное отклонение от симметрии. В остальных опытах скорость ударника составляет $246-250 \mathrm{~m} / \mathrm{s}$, а скорость разлета воды - 216- $257 \mathrm{~m} / \mathrm{s}$, что согласуется с расчетными оценками [1]. Колебание скорости разлета воды может быть связано с погрешностями измерения положения возмущенного фронта воды.

Результаты этой серии экспериментов не противоречат приведенным выше оценкам: в экспериментах угловое расположение нитей лески $2 \alpha=120^{\circ}$ является предельным значением и не исключает полностью возможности касания ударником стенки канала. В дальнейшем для значений диаметра ударника (34.5-34.6 mm) и диаметра канала $(35.0 \mathrm{~mm})$ можно будет устанавливать четыре нити лески диаметром $0.12 \mathrm{~mm}$.

Таким образом, описанные результаты экспериментов на ударной трубе указывают на возможность сохранения ориентации тонкого плоского ударника, ускоряемого в цилиндрическом канале давлением продуктов детонации смеси ацетилена с кислородом, при помощи ограничителей бокового смещения в виде нескольких нитей полимерной лески, расположенных равномерно по образующим поверхности канала.

\section{Благодарности}

Авторы выражают признательность В.П. Башурину, Л.В. Ктиторову и В.А. Ерошенко за полезные обсуждения, Ю.В. Алеханову и С.А. Ломтеву за техническую помощь.

\section{Конфликт интересов}

Авторы заявляют, что у них нет конфликта интересов.

\section{Список литературы}

[1] Баранов В.К., Георгиевская А.Б., Гук Д.Е., Замыслов Д.Н., Макаров С.А., Мешков Е.Е., Степушкин С.Н. // Письма в ЖТФ. 2016. Т. 42. В. 16. C. 1-6.

[2] Pesavento U., Wang Z.J. // Phys. Rev. Lett. 2004. V. 93. P. 144501.

[3] Andersen A., Pesavento U., Wang Z.J. // J. Fluid Mech. 2005. V. 541. P. 65-90.

[4] Башурин В.П., Ктиторов Л.В., Лазарева А.С. Расчетное моделирование механизмов стабилизации полета плоского ударника // Сб. тез. докл. Междунар. конф. „XIX Харитоновские тематические научные чтения“. Саров, 2017. C. 219-220.

[5] Алеханов Ю.В., Власов Ю.А., Дудин В.И., Левушов А.Е., Ломтев С.А., Мармышев В.В., Мешков Е.Е., Никулин А.А., Половников Е.A. // Вестн. Саровского физтеха. 2007. № 12. C. $57-61$. 